\title{
Post-Traumatic Stress and School Adaptation in Adolescent Survivors Five Years after the 2010 Yushu Earthquake in China
}

\author{
Shou Liu ${ }^{1,2}{ }^{,}$Li Lu ${ }^{3, *}$, , Zheng-Zhong Bai ${ }^{1}$, Min Su ${ }^{4}$, Zheng-Qing Qi ${ }^{1}$, Shi-Yu Zhang ${ }^{1}$, \\ Yuan Chen ${ }^{1}$, Bing-Yu Ao ${ }^{1}$, Feng-Zhen Cui ${ }^{1}$, Emmanuel Lagarde ${ }^{3, *}$ and Kehshin Lii ${ }^{2, *}$ \\ 1 Department of Public Health, Medical College, Qinghai University, Qinghai 810001, China; \\ liushou2004@aliyun.com (S.L.); baizz@126.com (Z.-Z.B.); qigaoyuan123@sina.com (Z.-Q.Q.); \\ shiyuzhang_886@sina.com (S.-Y.Z.); chen199419@126.com (Y.C.); bingbingyu_123@sina.com (B.-Y.A.); \\ cfz199510@163.com (F.-Z.C.) \\ 2 Department of Statistics, University of California, Riverside, 337 Olmsted Hall, UCR, Riverside, \\ CA 92521, USA \\ 3 Team IETO, Bordeaux Population Health Research Center, UMR U1219, INSERM, Université de Bordeaux, \\ 33076 Bordeaux, France \\ 4 School of Public Administration, Inner Mongolia University, Inner Mongolia 010021, China; \\ sumin1227@126.com \\ * Correspondence: liser@outlook.com (L.L.); emmanuel.lagarde@u-bordeaux.fr (E.L.); kslii@ucr.edu (K.L.)
}

Received: 20 September 2019; Accepted: 27 October 2019; Published: 29 October 2019

\begin{abstract}
Background: The devastating Ms 7.1 earthquake struck Yushu city, China, in 2010, leading to serious consequences and damage in the central Tibetan Plateau. This study aimed to assess school adaptation and post-traumatic stress disorder (PTSD) symptoms of adolescent survivors five years after the Yushu earthquake. (2) Methods: A large-scale, school-based mental health survey was conducted 5 years after the earthquake among Tibetan students in the city of Yushu using the Adolescent's School Adaptation Scale (ASAS) and the PTSD Checklist. (3) Results: A total of 1976 questionnaires were collected. A total of 30.7\% of Tibetan adolescents had poor school adaptation and $19.5 \%$ were estimated as having probable PTSD. Logistic regression showed that females (OR $=0.73,95 \%$ CI: 0.60-0.89), senior students (OR $=0.48,95 \%$ CI: $0.39-0.59)$, and those who participated in post-disaster reconstruction $(\mathrm{OR}=0.68,95 \% \mathrm{CI}$ : $0.54-0.85)$ were less likely to have poor school adaptation, while a positive association was observed among those buried under a collapsed building ( $\mathrm{OR}=1.47,95 \% \mathrm{CI}$ : 1.04-2.09) and those who experienced bereavement $(\mathrm{OR}=1.77,95 \% \mathrm{CI}: 1.27-2.45)$. Students who had experienced bereavement were also more likely to have PTSD (OR $=1.60,95 \%$ CI: 1.12-2.28). (4) Conclusions: The post-traumatic effects of the Yushu earthquake on Tibetan adolescents were severe and long-lasting. Sustainable long-term mental health services to help adolescents to restructure their mental health are necessary.
\end{abstract}

Keywords: adolescent; post-traumatic stress disorder (PTSD); school adaptation; Tibetan; Yushu earthquake

\section{Introduction}

The city of Yushu is the capital the Tibetan Autonomous Prefecture of Yu Shu and located in the southwest Qinghai province of China at an average altitude of 4493.4 meters with 100,000 inhabitants. The city was hit by an earthquake (Ms 7.1) in 2010, which caused the death of 2698 people and injured $12,135[1,2]$. It has been estimated that a minimum of $85 \%$ of houses were destroyed in Yushu county, 
almost all (99\%) houses collapsed in the most badly affected village, and $70 \%$ of school buildings collapsed [1].

The earthquake broke down basic social infrastructures and had a profound impact on various aspects of the quality of life of local residents [3,4]. In the early post-disaster reconstruction period, local government and research institutions focused primarily on providing emergency medical services and coping with stress disorders for earthquake survivors [5,6]. In addition, local healthcare services established outreach mental health services in collaboration with social workers in schools and medical institutions.

Several studies have assessed individuals' mental health and traumatic symptoms following the earthquakes [7-9], where the detrimental psychological effects of earthquakes often persist for a decade or longer [10]. Previous studies have identified the associations between post-traumatic stress disorder (PTSD) symptoms, anxiety, and depression and the experience of the earthquake $[1,8,11,12]$. Sleep disorders have also been reported by earthquake survivors [13,14]. A study conducted among 2080 survivors in Wenchuan found that although the prevalence of PTSD, anxiety, and depression disorders decreased over time after the earthquake, its effect on the mental health remained severe one year later, with a $40.1 \%$ prevalence of PTSD [15]. Another study showed that the prevalence of PTSD was $44.5 \%$ among 278 Lushan survivors 13 to 16 months after the earthquake [16].

Large-scale screening programs to assess the extent of post-disaster psychiatric disorders among adolescents have been continuously conducted $[2,3,17]$. The family environment was reportedly associated with adolescents' PTSD [18]. Studies conducted on adolescents after the Yushu earthquake were all related to PTSD [19,20]; no studies have been so far conducted on the adolescents' school adaptation. In literature, school adaptation difficulties were described among sexually abused girls [21], and longitudinal studies showed that stress significantly decreases subsequent school performance and completion $[22,23]$. The issue of adolescents' school adaptation and adjustment in the context of a strong earthquake therefore needs to be investigated. Due to the population composition of the Tibetan Autonomous Prefecture of Yu Shu, Tibetans account for $98 \%$ of the total population [24]. Survivors in Yushu earthquake are known to be Tibetan and have a belief in Tibetan Buddhism, where the belief could affect various aspects of adolescent survivors' social and daily life [2], such as the school adaptation and perspectives on the loss of family members, etc.

The present study aimed to assess the 5-year consequences and associated factors of the 2010 Yushu earthquake on school adaptation and PTSD symptoms of Tibetan adolescents. Based on findings from previous post-earthquake studies, we made the hypothesis that the school maladaptation and PTSD symptoms among student survivors 5 years after the Yushu earthquake would still be common.

\section{Materials and Methods}

\subsection{Study Design, Participants, and Data Collection}

A large-scale, school-based mental health survey was conducted on Tibetan students/adolescents attending the Tibetan boarding school (The Second Middle School of Yushu) in Yushu city between June and September 2015. There are two boarding middle schools in Yushu city, where students coming from different areas of the city including the remote areas generates a diversified group of students in this school, which guarantees the representativeness of the sample. Tibetan middle school students who survived the Yushu earthquake were included using a cluster-sampling method. Due to the objective stating that we only focus on the symptoms of minority students, Han ethnic students were excluded from this study. Twenty students were randomly selected for a pilot survey and standardized answers were generated. School teachers were trained to introduce the study and administer the questionnaires.

Teachers introduced the objectives and procedure of the survey to all students before distributing questionnaires in each class and all students were informed of the principle of anonymity and voluntary participation regarding the survey. The teacher distributed the questionnaires to the entire class and the students were asked to return their questionnaires after completing it within approximately $30 \mathrm{~min}$. 
All students involved verbally agreed to participate in the survey and written informed consent was provided by their guardians in accordance with local ethical regulations for epidemiological surveys.

\subsection{Assessment Tools}

The questionnaire was divided into three parts: (1) socio-demographic characteristics (gender, grade, and adolescents' different earthquake experiences, e.g., injury, injury of a family member, buried under debris, bereavement, property damage, living in the hardest-hit area, and involved in post-disaster reconstruction; (2) Adolescent's School Adaptation Scale (ASAS); and (3) PTSD symptoms. For consistency, the original Chinese questionnaires were first translated into the Tibetan language and then translated back into Chinese by different Tibetan experts to compare the differences between the translations and modify the Tibetan translation accordingly.

The Adolescent's School Adaptation Scale (ASAS) was used to assess the participants' school adaptability five years after the earthquake, where the Cronbach alpha of the scale was 0.78 [25]. Prior to the formal investigation, a preliminary survey was conducted in Tibetan adolescents to evaluate the measuring quality of this scale. The test-retest reliability and content validity of the scale among the samples were 0.82 and 0.89 , respectively. Test-retest reliability is the correlation coefficient between the results of a repeat measurement on the same participants (0.82) and the content validity is the consistency between participants' understanding of, and answer to, the question and what the item designer wanted to ask was 0.89 (content validity ratio). The ASAS assessed eight subtypes of adaptability by using 54 items: (a) stress from the teacher ( 7 items), (b) principle breach (10 items), (c) academic anxiety (11 items), (d) sense of justice (7 items), (e) peer relationships (6 items), (f) school attractiveness (4 items), (i) competition awareness (5 items), and (j) teacher-student relationship (4 items). There were five possible responses to each item from 1 ("completely agree") to 5 ("completely disagree"). Poor adaptability for a given subtype was defined as the average score of the corresponding items being greater than or equal to 3 . Overall poor school adaptability was defined as the average score of the all items being greater or equal to 3 [25].

The Post-Traumatic Stress Disorder (PTSD) Checklist was used to assess the PTSD [26]. It is a widely used self-reported scale [2,27], and the Chinese version has been validated with good psychometric properties (Cronbach's alpha above 0.77) [28]. It consists of 17 items and represents the three following dimensions: (a) re-experiencing symptoms (5 items), (b) avoidance (7 items), and (c) hyper-arousal (5 items). Each symptom was self-assessed on a five-point Likert scale ranging from 1 ("not at all") to 5 ("extremely"). Adolescents with a score $\geq 44$ were considered to have PTSD and a higher score represented severe symptoms [2,28].

\subsection{Data Analysis}

Independent-sample $t$-tests and chi-square $\left(\chi^{2}\right)$ tests were used for the univariate analyses. Logistic regression analyses were conducted to explore the associations by setting the ASAS and PTSD as dependent variables separately. All predictors in preliminary analyses were considered as independent variables. A $p$-value less than 0.05 was considered statistically significant. All statistical procedures were completed using STATA version 12.0 (Stata Corporation, College Station, TX, USA).

\subsection{Ethics Approval}

This study was approved by the the principals of Yushu Second Prefecture Middle School and The Ethnic Committee of the Medical College of Qinghai University, authorization number: QHMC-2015-00001-PH. 


\section{Results}

\subsection{Basic Characteristics of the Participants}

A total of 2000 questionnaires were distributed and collected with a response rate of $100 \%$. Questionnaires from six students from the Han ethnic group and 18 from students who did not experience the earthquake were excluded. Therefore, 1976 (98.8\%) collected questionnaires were used in this study with 1146 (58.0\%) female and 634 (32.1\%) junior students. The basic demographic characteristics and traumatic experiences of the students are presented in Table 1 . The proportion of participants who reported personal injury, injury of a family member, burial under debris, bereavement, and property damage were $15.5 \%, 17.8 \%, 9.0 \%, 11.5 \%$, and $31.3 \%$, respectively. The participants who were living in the hardest-hit area were $32.5 \%$, and $35.8 \%$ were involved in post-disaster reconstruction.

Table 1. Demographic characteristics and traumatic experience among adolescent survivors of the Yushu earthquake, China $(N=1976)$.

\begin{tabular}{|c|c|c|c|c|c|c|c|}
\hline \multirow[b]{2}{*}{ Title } & \multirow[b]{2}{*}{ Total $(\%)$} & \multicolumn{2}{|c|}{ Grade } & \multirow[b]{2}{*}{$\chi^{2}(p)$} & \multicolumn{2}{|c|}{ Gender } & \multirow[b]{2}{*}{$\chi^{2}(p)$} \\
\hline & & $\underset{(n=634)}{\text { Junior }}$ & $\begin{array}{c}\text { Senior } \\
(n=1342)\end{array}$ & & $\begin{array}{c}\text { Male } \\
(n=830)\end{array}$ & $\begin{array}{c}\text { Female } \\
(n=1146)\end{array}$ & \\
\hline Injury of family member (Yes) & $353(17.8)$ & $112(17.7)$ & $240(17.9)$ & $0.01(0.91)$ & $146(17.6)$ & $206(18.0)$ & $0.05(0.83)$ \\
\hline Buried under debris (Yes) & $178(9.0)$ & $57(9.0)$ & $121(9.0)$ & $0.0004(0.99)$ & $87(10.5)$ & $91(7.9)$ & $3.79(0.051)$ \\
\hline Bereavement (Yes) & $228(11.5)$ & $57(9.0)$ & $171(12.7)$ & $5.94(\mathbf{0 . 0 1 5})$ & $87(10.5)$ & $146(12.7)$ & $3.86(0.049)$ \\
\hline $\begin{array}{l}\text { Involved in post-disaster } \\
\text { reconstruction (Yes) }\end{array}$ & $708(35.8)$ & $205(32.3)$ & $503(37.5)$ & $4.96(\mathbf{0 . 0 3})$ & $297(35.8)$ & $411(35.9)$ & $0.001(0.97)$ \\
\hline Total (\%) & 1976 & $634(32.1)$ & $1342(67.9)$ & - & $830(42.0)$ & $1146(58.0)$ & - \\
\hline
\end{tabular}

* Adolescents living within $60 \mathrm{~km}$ of the epicenter. The differences in the proportion of the traumatic experiences were analyzed according to different gender and grade groups. Bold values: $p<0.05$.

\subsection{Predictors of School Maladaptation}

The average ASAS score was $21.58(\mathrm{SD}=2.74)$ among the 1976 participants, ASAS subtypes with the highest average scores were stress from the teacher $(3.27$; SD $=0.60)$, academic anxiety ( 3.25 ; $\mathrm{SD}=0.45)$, and competition awareness $(2.71 ; \mathrm{SD}=0.58)$. The prevalence of poor school adaptability was 30.7\% ( $n=606,95 \%$ CI: $28.6 \%-32.8 \%)$. Social demographic characteristics of school adaptation and its subtypes are shown in Table 2 and Table S1, respectively.

Table 2. Univariate analyses of ASAS among adolescent survivors.

\begin{tabular}{|c|c|c|c|c|c|c|}
\hline \multirow[t]{2}{*}{ Variables } & \multicolumn{2}{|c|}{$\begin{array}{l}\text { Good School Adaptation } \\
\qquad(n=1370)\end{array}$} & \multicolumn{2}{|c|}{$\begin{array}{l}\text { Poor School Adaptation } \\
\qquad(n=606)\end{array}$} & \multicolumn{2}{|c|}{ Statistics } \\
\hline & $n$ & $\%$ & $n$ & $\%$ & $\chi^{2}$ & $p$ \\
\hline Gender (Female) & 828 & 60.4 & 318 & 52.5 & 10.94 & 0.001 \\
\hline Grade (Senior) & 999 & 72.9 & 343 & 56.6 & 51.35 & $<0.001$ \\
\hline Injury & 193 & 14.1 & 114 & 18.8 & 7.15 & 0.008 \\
\hline Injury of a family member (Yes) & 222 & 16.2 & 130 & 21.5 & 7.90 & 0.005 \\
\hline Buried under debris (Yes) & 106 & 7.7 & 72 & 11.9 & 8.80 & 0.003 \\
\hline Bereavement (Yes) & 135 & 9.9 & 93 & 15.3 & 12.42 & $<0.001$ \\
\hline Property damage (Yes) & 435 & 31.8 & 184 & 30.4 & 0.38 & 0.54 \\
\hline Living in hardest-hit area (Yes) & 451 & 32.9 & 192 & 31.7 & 0.29 & 0.59 \\
\hline $\begin{array}{l}\text { Involved in post-disaster } \\
\text { reconstruction (Yes) }\end{array}$ & 524 & 38.2 & 184 & 30.4 & 11.36 & 0.001 \\
\hline PTSD (Yes) & 278 & 20.3 & 108 & 17.8 & 1.63 & 0.20 \\
\hline
\end{tabular}

Note: ASAS: Adolescent's School Adaptation Scale; PTSD: Post-Traumatic Stress Disorder. Bold values: $p<0.05$.

Logistic multivariate regression showed that female (OR $=0.73,95 \% \mathrm{CI}: 0.60-0.89, p=0.002)$ and senior $(\mathrm{OR}=0.48,95 \% \mathrm{CI}: 0.39-0.59, p<0.001)$ students, and those who where involved in post-disaster reconstruction $(\mathrm{OR}=0.68,95 \% \mathrm{CI}: 0.54-0.85, p=0.001)$, were less likely to have school maladaptation, 
while those who were buried under a collapsed building (OR $=1.47,95 \%$ CI: $1.04-2.09, p=0.03$ ) and suffered bereavement (OR $=1.77,95 \%$ CI: 1.27-2.45, $p=0.001$ ) had a higher risk of poor school adaptation. PTSD symptoms showed weak evidence for a positive relationship with overall school maladaptation (OR $=0.78,95 \% \mathrm{CI}: 0.60-1.003, p=0.053$ ). The results of the logistic regressions on the associations between independent variables and the prevalence of poor school adaptation are shown in Table 3.

Table 3. Logistic regression analyses on the associations between independent variables and school maladaptation $(N=1976)$.

\begin{tabular}{|c|c|c|c|c|}
\hline \multirow{2}{*}{ Variables } & \multirow{2}{*}{ OR } & \multirow{2}{*}{$p$} & \multicolumn{2}{|c|}{$95 \%$ CI } \\
\hline & & & Lower & Upper \\
\hline Gender (Female) & 0.73 & 0.002 & 0.60 & 0.89 \\
\hline Grade (Senior) & 0.48 & $<0.001$ & 0.39 & 0.59 \\
\hline Injury (Yes) & 1.28 & 0.093 & 0.96 & 1.72 \\
\hline Injury of a family member (Yes) & 1.29 & 0.088 & 0.96 & 1.73 \\
\hline Buried under debris (Yes) & 1.47 & 0.030 & 1.04 & 2.09 \\
\hline Bereavement (Yes) & 1.77 & 0.001 & 1.27 & 2.45 \\
\hline Property damage (Yes) & 0.85 & 0.204 & 0.67 & 1.09 \\
\hline Living in hardest-hit area (Yes) & 0.84 & 0.171 & 0.66 & 1.08 \\
\hline Involved in post-disaster reconstruction (Yes) & 0.68 & 0.001 & 0.54 & 0.85 \\
\hline PTSD (Yes) & 0.78 & 0.053 & 0.60 & 1.003 \\
\hline
\end{tabular}

\subsection{Predictors of PTSD}

The overall average PTSD score was 41.20 (SD = 10.98), and the average scores for re-experiencing symptoms, persistent avoidance symptoms, and hyper-arousal symptoms were $12.38(\mathrm{SD}=3.87), 16.67$ $(\mathrm{SD}=4.94)$, and $12.15(\mathrm{SD}=4.16)$, respectively. There were $19.5 \%(n=386,95 \% \mathrm{CI}: 17.8 \%-21.4 \%)$ of adolescents who were positive for PTSD. The univariate analyses of PTSD predictors are shown in Table 4.

Table 4. Univariate analyses of PTSD among adolescent survivors.

\begin{tabular}{lcccccc}
\hline \multicolumn{1}{c}{ Variables } & Without PTSD $(\boldsymbol{N}=\mathbf{1 5 9 0})$ & \multicolumn{2}{c}{ With PTSD $(\boldsymbol{N}=\mathbf{3 8 6})$} & \multicolumn{2}{c}{ Statistics } \\
\hline & $\boldsymbol{n}$ & $\mathbf{\%}$ & $\boldsymbol{n}$ & $\mathbf{\%}$ & $\boldsymbol{\chi}^{\mathbf{2}}$ & $\boldsymbol{p}$ \\
Gender (Female) & 926 & 58.2 & 220 & 57.0 & 0.20 & 0.66 \\
Grade (Senior) & 1080 & 67.9 & 262 & 67.9 & 0.0003 & 0.99 \\
Injury (Yes) & 231 & 14.5 & 76 & 19.7 & 6.30 & $\mathbf{0 . 0 1}$ \\
Injury of a family member (Yes) & 269 & 16.9 & 83 & 21.5 & 4.46 & $\mathbf{0 . 0 4}$ \\
Buried under debris (Yes) & 132 & 8.3 & 46 & 11.9 & 4.95 & $\mathbf{0 . 0 3}$ \\
Bereavement (Yes) & 164 & 10.3 & 64 & 16.6 & 11.95 & $<\mathbf{0 . 0 0 1}$ \\
Property damage (Yes) & 496 & 31.2 & 123 & 31.9 & 0.06 & 0.80 \\
Living in hardest-hit area (Yes) & 511 & 32.1 & 132 & 34.2 & 0.60 & 0.44 \\
Involved in post-disaster & 570 & 35.8 & 138 & 35.8 & 0.001 & 0.97 \\
reconstruction (Yes) & & & & & & \\
\hline
\end{tabular}

PTSD: Post-Traumatic Stress Disorder. Bold values: $p<0.05$.

Multivariate logistic regression suggested that participants who experienced bereavement $(\mathrm{OR}=1.60,95 \%$ CI: $1.12-2.28 p=0.009)$ were more likely to report PTSD (Table 5). 
Table 5. Logistic regression analyses on the associations between independent variables and PTSD $(N=1976)$.

\begin{tabular}{lcccc}
\hline \multicolumn{1}{c}{ Variables } & \multirow{2}{*}{ OR } & $\boldsymbol{*}$ & \multicolumn{2}{c}{ 95\% CI } \\
\cline { 4 - 5 } & & & Lower & Upper \\
\hline Gender (Female) & 0.96 & 0.697 & 0.76 & 1.20 \\
Grade (Senior) & 0.99 & 0.918 & 0.78 & 1.26 \\
Injury (Yes) & 1.29 & 0.120 & 0.94 & 1.78 \\
Injury of a family member (Yes) & 1.10 & 0.583 & 0.79 & 1.52 \\
Buried under debris (Yes) & 1.28 & 0.205 & 0.87 & 1.88 \\
Bereavement (Yes) & 1.60 & $\mathbf{0 . 0 0 9}$ & 1.12 & 2.28 \\
Property damage (Yes) & 0.87 & 0.340 & 0.66 & 1.15 \\
Living in hardest hit area (Yes) & 0.96 & 0.774 & 0.73 & 1.27 \\
Involved in post-disaster reconstruction Yes) & 0.94 & 0.636 & 0.73 & 1.21 \\
PTSD (Yes) & 0.96 & 0.697 & 0.76 & 1.20 \\
\hline
\end{tabular}

Adjusted $\mathrm{R}^{2}=0.09$. ASAS: Adolescent's School Adaptation Scale; PTSD: Post-Traumatic Stress Disorder. Bold values: $p<0.05$.

\section{Discussion}

Exposure to a range of traumatic events can cause detrimental consequences for survivors' mental health and wellbeing $[29,30]$. This study identifies that the prevalence of poor school adaptation among Tibetan adolescents 5 years after the 2010 Yushu earthquake was $30.7 \%$, and $19.5 \%$ of adolescents met the criteria on the PTSD checklist. Of note, the interventions for post-traumatic stress must be carried out in children and adolescents 2-6 months after the traumatic events due to the deterioration of the condition and decreased effectiveness of the therapy interventions [31]. However, it is also important to evaluate the long-term influence of the traumatic event from an epidemiological viewpoint.

Poor school adaptation was common among the participants in our study. Although a wide range of psychiatric disorders have been described previously among adolescents who experienced a disaster [17], the prevalence of poor school adaptation after an earthquake has been rarely explored so far. One clinic-based study identified that $54 \%$ of sexually abused girls presented disabilities in school adaptation, which was higher than our figure [21]. Contrary to our study, which examined eight subscales, the authors used some of the variables from the Child Behavior Checklist [32] to assess three domains of school adaptation, i.e., academic performance, social functioning, and externalized behaviors [21]. Another previous study identified that school non-completion were more frequent among those students who had more life-changing events and higher level of stress [23]. Further works are clearly needed to describe the vulnerability to school adaptation and dropping out induced by stressful life events.

Males, junior students, and those who did not participate in post-disaster reconstruction were more likely to experience poor school adaptation after the earthquake over the long term. Females were found more prone to report psychological effects after an earthquake in other studies [15,18], although school adaptation was rarely studied. One cohort study found that younger children were more likely to report PTSD symptoms following the 1999 Athens earthquake, probably because younger children may be less able to deal with traumatic experiences than those who are older, both emotionally and cognitively [9]. Participating in post-disaster reconstruction mainly referred to the activities within the adolescents' power, such as participating in the cleanup of the ruins, rearranging the home, etc., which provided adolescents with the chance to integrate into group activities and benefit from more social support, which in turn could help them to develop positive attitudes toward life and offset the negative effects of traumatic events on adaptation [22]. Those who have been buried under a collapsed building and who experienced bereavement were more likely to report poor school adaptation. With respect to PTSD, other studies unsurprisingly evidenced that people who experienced severe traumatic events are more likely to suffer from PTSD [2]. There was weak evidence on the inverse association between PTSD and school maladaptation. One possible explanation is that those with PTSD sought or accepted 
more social support in the hope of alleviating their suffering [33]. However, the content of our study did not provide information on social support and the hypothesis cannot be tested.

Published studies on PSTD after earthquakes reported a wide range of PCL scores and prevalence. The scores of our participants were higher than another study that also focused on Tibetan adolescents 4 years after the earthquake $(36.8, \mathrm{SD}=12.1)$, while the prevalence between their study and ours was similar (19.3\%) [2]. Much higher prevalences have been reported elsewhere: 37.5\% among high school students 10 months after an earthquake in L'Aquila, Italy [7]; and 20.9\% among women adults (who were pregnant during or after the earthquake) 4 years after the Wenchuan earthquake in China [34]; and $33.7 \%$ among the survivors who were in the hard-hit areas 3-4 months after the Yushu earthquake [1]. Almost $65 \%$ of Pakistani earthquake survivors met the criteria for probable PTSD 3 years after the initial shock [35]. The figure in our study was over twice as high as those reported among Taiwanese survivors 6 months after the Chi-Chi earthquake in 1999 (7.9\%) [36]. The difference in published studies may be due to contextual factors, such as regional socio-economical differences, assessment and diagnostic methods, or assessment tools with differences in terms of cut-off values, time points, the degree of traumatic exposure, destructive extent of the events, etc. [1,29,35].

Adolescents who had experienced bereavement due to the earthquake were more likely to be positive for PTSD, those suffered an injury also showed weak evidence of a positive association. Even though the prevalence of PTSD varies widely among studies, personal injury and a sudden and/or violent loss of a loved or closed person during a natural disaster have been repeatedly reported to have an adverse influence on individuals' mental health, such as resulting in PTSD [37-39]. For example, survivors who were injured during the 2004 tsunami in Tamil Nadu, India, were approximately 3 times as likely to report PTSD [40]. Bereavement experience was also reported to be positively correlated with PTSD among high school girls who survived the tsunami [41]. Children who had lost family members after a 7.4-magnitude earthquake in Turkey were more likely to have PTSD with comorbid depression [11]. Previous studies reported that among the earthquake survivors, PTSD was more common among women, those with less social support, and those with low income $[1,7,42]$, which was not confirmed in our study.

Treatment and intervention programs of traumatized adolescents should be launched in view of the long-lasting effects of the earthquake. Integrated efforts from the family, school, community, and society may serve to provide a collaborative trauma systems therapy (TST) approach for adolescents [43,44]. The direct care staff members in our study are the teachers that adults spend the most time with [44]; therefore, training regarding the ability to recognize adolescents' emotional state and relevant coping methods could be performed among teachers. In addition, arts-based mindfulness group activities that can enhance the sense of collective cohesion and teamwork [45] and a rotating appointment of class cadre roles that could reinforce and expand a person's conception of responsibility [46] are supposed to be effective and could help to restructure adolescents' mental health.

This study explored factors associated with poor school adaptation and PTSD among adolescents 5 years after the earthquake, which could provide government and related institutions with the evidence to implement long-term intervention programs for school-aged populations who have experienced traumatic events in China. However, there are some limitations in this study. First, the participants were recruited from a single school rather than from several randomly selected schools, which may limit the generalizability of the results. Second, some potentially relevant information, such as social support, economic level, etc., was not collected in our study. In addition, the scales used in this study were not validated in the Tibetan language, and the ASAS scale was not nationally validated and commonly used, which made it impossible to make comparisons between our results and those from other studies. Finally, due to the exploratory nature of the present study, the causality between possible factors and poor school adaptation and PTSD cannot be established. 


\section{Conclusions}

In conclusion, the psychological and academic consequences of the Yushu earthquake on Tibetan adolescents were severe and long-lasting, underscoring the need to provide sustainable mental health services and intervention programs to help adolescents restructure their mental health after the disaster. Further studies and therapy interventions should be performed after the traumatic events to avoid the conversion of related disadvantages from acute to chronic status.

Supplementary Materials: The following are available online at http://www.mdpi.com/1660-4601/16/21/4167/s1, Table S1: Univariate analyses of ASAS and subscales among adolescent survivors $(N=1976)$.

Author Contributions: S.L. and L.L. designed the study. S.L., Z.-Z.B., Z.-Q.Q., S.-Y.Z., Y.C., B.-Y.A., and F.-Z.C. conducted the data collection. S.L., L.L., and M.S. analyzed and interpreted the data. S.L. and L.L. drafted the manuscript. E.L. and K.L. critically revised the manuscript. All the authors approved the final version of this article for publication.

Funding: This study was supported by the Ministry of Education of the People's Republic of China (No: 14YJCZH101) and has been supported by the Qinghai Province Government on the Plan of Thousands of High Level of Innovative Talents. Shou Liu was supported by a China Scholarship Council (No: 201408635014) for further study at University of California as a visiting scholar.

Acknowledgments: This survey was conducted by the research team from Medical College of Qinghai University in collaboration with The Second Middle School of Yushu. We thank Zhang Wen from The Second Middle School of Yushu, and Fabin Zhang, Huilian Yang, Bin Li, Weiqi Du, Haijing Wang, Zhancui Dang, Yao Zhao, and Lei Zhao from Medical College of Qinghai University for their hard work in successfully collecting data.

Conflicts of Interest: The authors declare no conflict of interest.

\section{References}

1. Zhang, Z.; Wang, W.; Shi, Z.; Wang, L.; Zhang, J. Mental health problems among the survivors in the hard-hit areas of the Yushu earthquake. PLoS ONE 2012, 7, e46449. [CrossRef] [PubMed]

2. Dongling, L.; Hui, C.; Ling, M.; Wenqian, B.; Zailiang, L.; Changying, C. Post-traumatic stress disorder and its predictors among bereaved Tibetan adolescents four years after the Yushu earthquake: A cross-sectional survey in China. J. Clin. Nurs. 2017, 26, 1095-1105. [CrossRef] [PubMed]

3. Goenjian, A.K.; Roussos, A.; Steinberg, A.M.; Sotiropoulou, C.; Walling, D.; Kakaki, M.; Karagianni, S. Longitudinal study of PTSD, depression, and quality of life among adolescents after the Parnitha earthquake. J. Affect. Disord. 2011, 133, 509-515. [CrossRef] [PubMed]

4. Wu, H.C.; Chou, P.; Chou, F.H.; Su, C.Y.; Tsai, K.Y.; Ou-Yang, W.C.; Su, T.T.; Chao, S.S.; Sun, W.J.; Chen, M.C. Survey of quality of life and related risk factors for a Taiwanese village population 3 years post-earthquake. Aust. New Zealand J. Psychiatry 2006, 40, 355-361. [CrossRef] [PubMed]

5. Zhang, L.; Liu, X.; Li, Y.; Liu, Y.; Liu, Z.; Lin, J.; Shen, J.; Tang, X.; Zhang, Y.; Liang, W. Emergency medical rescue efforts after a major earthquake: Lessons from the 2008 Wenchuan earthquake. Lancet (Lond. Engl.) 2012, 379, 853-861. [CrossRef]

6. Liang, Y.; Cao, R.X. Employment assistance policies of Chinese government play positive roles! The impact of post-earthquake employment assistance policies on the health-related quality of life of Chinese earthquake populations. Soc. Indic. Res. 2015, 120, 835-857. [CrossRef]

7. Dell'Osso, L.; Carmassi, C.; Massimetti, G.; Daneluzzo, E.; Di Tommaso, S.; Rossi, A. Full and partial PTSD among young adult survivors 10 months after the L'Aquila 2009 earthquake: Gender differences. J. Affect. Disord. 2011, 131, 79-83. [CrossRef]

8. Fan, F.; Zhang, Y.; Yang, Y.Y.; Mo, L.; Liu, X.C. Symptoms of posttraumatic stress disorder, depression, and anxiety among adolescents following the 2008 Wenchuan earthquake in China. J. Trauma. Stress 2011, 24, 44-53. [CrossRef]

9. Giannopoulou, I.; Strouthos, M.; Smith, P.; Dikaiakou, A.; Galanopoulou, V.; Yule, W. Post-traumatic stress reactions of children and adolescents exposed to the Athens 1999 earthquake. Eur. Psychiatry J. Assoc. Eur. Psychiatry. 2006, 21, 160-166. [CrossRef]

10. Seplaki, C.L.; Goldman, N.; Weinstein, M.; Lin, Y.H. Before and after the 1999 Chi-Chi earthquake: Traumatic events and depressive symptoms in an older population. Soc. Sci. Med. 2006, 62, 3121-3132. [CrossRef] 
11. Eksi, A.; Braun, K.L.; Ertem-Vehid, H.; Peykerli, G.; Saydam, R.; Toparlak, D.; Alyanak, B. Risk factors for the development of PTSD and depression among child and adolescent victims following a 7.4 magnitude earthquake. Int. J. Psychiatry Clin. Pract. 2007, 11, 190-199. [CrossRef] [PubMed]

12. Pynoos, R.S.; Goenjian, A.; Tashjian, M.; Karakashian, M.; Manjikian, R.; Manoukian, G.; Steinberg, A.M.; Fairbanks, L.A. Post-traumatic stress reactions in children after the 1988 Armenian earthquake. Br. J. Psychiatry J. Ment. Sci. 1993, 163, 239-247. [CrossRef] [PubMed]

13. Geng, F.; Fan, F.; Mo, L.; Simandl, I.; Liu, X. Sleep problems among adolescent survivors following the 2008 Wenchuan earthquake in China: A cohort study. J. Clin. Psychiatry 2013, 74, 67-74. [CrossRef] [PubMed]

14. Wood, J.M.; Bootzin, R.R.; Rosenhan, D.; Nolen-Hoeksema, S.; Jourden, F. Effects of the 1989 San Francisco earthquake on frequency and content of nightmares. J. Abnorm. Psychol. 1992, 101, 219-224. [CrossRef] [PubMed]

15. Wu, Z.; Xu, J.; He, L. Psychological consequences and associated risk factors among adult survivors of the 2008 Wenchuan earthquake. BMC Psychiatry 2014, 14, 126. [CrossRef] [PubMed]

16. Xie, Z.; Xu, J.; Wu, Z. Mental health problems among survivors in hard-hit areas of the 5.12 Wenchuan and 4.20 Lushan earthquakes. J. Ment. Health (Abingdonengland) 2017, 26, 43-49. [CrossRef] [PubMed]

17. Kar, N.; Bastia, B.K. Post-traumatic stress disorder, depression and generalised anxiety disorder in adolescents after a natural disaster: A study of comorbidity. Clin. Pract. Epidemiol. Ment. Health 2006, 2, 17. [CrossRef]

18. Garfin, D.R.; Silver, R.C.; Gil-Rivas, V.; Guzmán, J.; Murphy, J.M.; Cova, F.; Rincón, P.P.; Squicciarini, A.M.; George, M.; Guzmán, M.P. Children's reactions to the 2010 Chilean earthquake: The role of trauma exposure, family context, and school-based mental health programming. Psychol. Trauma Theoryresearchpracticeand Policy 2014, 6, 563. [CrossRef]

19. De Young, A.C.; Haag, A.C.; Kenardy, J.A.; Kimble, R.M.; Landolt, M.A. Coping with Accident Reactions (CARE) early intervention programme for preventing traumatic stress reactions in young injured children: Study protocol for two randomised controlled trials. Trials 2016, 17, 362. [CrossRef]

20. Jin, Y.; Li, J. Prospective study of posttraumatic stress in adolescents 6 and 24 months after the 2010 yushu earthquake in China. J. Nerv. Ment. Dis. 2015, 203, 679-683. [CrossRef]

21. Daignault, I.V.; Hebert, M. Profiles of school adaptation: Social, behavioral and academic functioning in sexually abused girls. Child Abus. Negl. 2009, 33, 102-115. [CrossRef] [PubMed]

22. DuBois, D.L.; Felner, R.D.; Brand, S.; Adan, A.M.; Evans, E.G. A prospective study of life stress, social support, and adaptation in early adolescence. Child Dev. 1992, 63, 542-557. [CrossRef] [PubMed]

23. Hess, R.S.; Copeland, E.P. Students' stress, coping strategies, and school completion: A longitudinal perspective. Sch. Psychol. Q. 2001, 16, 389-405. [CrossRef]

24. Local Records Compilation Committee of The Yu Shu Tibetan Autonomous Prefecture. Yearbook of Yushu Tibetan autonomous prefecture. Qinghai Natl. Publ. House 2016, 12, 41.

25. Qi, Z.Q. The comparison of the school-adaptation-feeling between the only-child and the non-only-child middle school students (In Chinese). China J. Health Psychol. 2009, 17, 64-65. [CrossRef]

26. Blanchard, E.B.; Jones-Alexander, J.; Buckley, T.C.; Forneris, C.A. Psychometric properties of the PTSD checklist (PCL). Behav. Res. Ther. 1996, 34, 669-673. [CrossRef]

27. Weathers, F.W.; Litz, B.T.; Herman, D.S.; Huska, J.A.; Keane, T.M. The PTSD Checklist (PCL): Reliability, validity, and diagnostic utility. Proceedings of Annual Convention of the International Society for Traumatic Stress Studies, San Antonio, TX, USA, 24-27 October 1993.

28. Li, H.; Wang, L.; Shi, Z.; Zhang, Y.; Wu, K.; Liu, P. Diagnostic utility of the PTSD checklist in detecting ptsd in Chinese earthquake victims. Psychol. Rep. 2010, 107, 733-739. [CrossRef]

29. Galea, S.; Nandi, A.; Vlahov, D. The epidemiology of post-traumatic stress disorder after disasters. Epidemiol. Rev. 2005, 27, 78-91. [CrossRef]

30. Yule, W.; Bolton, D.; Udwin, O.; Boyle, S.; O’Ryan, D.; Nurrish, J. The long-term psychological effects of a disaster experienced in adolescence: I: The incidence and course of PTSD. J. Child Psychol. Psychiatryand Allied Discip. 2000, 41, 503-511. [CrossRef]

31. Meiser-Stedman, R.; Smith, P.; McKinnon, A.; Dixon, C.; Trickey, D.; Ehlers, A.; Clark, D.M.; Boyle, A.; Watson, P.; Goodyer, I.; et al. Cognitive therapy as an early treatment for post-traumatic stress disorder in children and adolescents: A randomized controlled trial addressing preliminary efficacy and mechanisms of action. J. Child Psychol. Psychiatryand Allied Discip. 2017, 58, 623-633. [CrossRef] 
32. Achenbach, T.M.; Rescorla, L.A. Manual for the ASEBA School-Age Forms \& Profiles: Child Behavior Checklist for Ages 6-18, Teacher's Report Form, Youth Self-Report: An Integrated System of Multi-Informant Assessment; University of Vermont, Research Center for Children Youth \& Families: Burlington, VT, USA, 2001.

33. Xu, J.; Dai, J.; Rao, R.; Xie, H. The association between exposure and psychological health in earthquake survivors from the Longmen Shan Fault area: The mediating effect of risk perception. BMC Public Health 2016, 16, 417. [CrossRef] [PubMed]

34. Cai, D.; Zhu, Z.; Sun, H.; Qi, Y.; Xing, L.; Zhao, X.; Wan, Q.; Su, Q.; Li, H. Maternal PTSD following exposure to the Wenchuan earthquake is associated with impaired mental development of children. PloS ONE 2017, 12, e0168747. [CrossRef] [PubMed]

35. Feder, A.; Ahmad, S.; Lee, E.J.; Morgan, J.E.; Singh, R.; Smith, B.W.; Southwick, S.M.; Charney, D.S. Coping and PTSD symptoms in Pakistani earthquake survivors: Purpose in life, religious coping and social support. J. Affect. Disord. 2013, 147, 156-163. [CrossRef] [PubMed]

36. Chou, F.H.; Su, T.T.; Chou, P.; Ou-Yang, W.C.; Lu, M.K.; Chien, I.C. Survey of psychiatric disorders in a Taiwanese village population six months after a major earthquake. J. Formos. Med Assoc. Taiwan yi zhi 2005, 104, 308-317.

37. Kristensen, P.; Weisaeth, L.; Heir, T. Bereavement and mental health after sudden and violent losses: A review. Psychiatry 2012, 75, 76-97. [CrossRef]

38. Kristensen, P.; Weisaeth, L.; Heir, T. Psychiatric disorders among disaster bereaved: An interview study of individuals directly or not directly exposed to the 2004 tsunami. Depress. Anxiety 2009, 26, 1127-1133. [CrossRef]

39. Pyari, T.T.; Kutty, R.V.; Sarma, P.S. Risk factors of post-traumatic stress disorder in tsunami survivors of Kanyakumari District, Tamil Nadu, India. Indian J. Psychiatry 2012, 54, 48-53. [CrossRef]

40. Kumar, M.S.; Murhekar, M.V.; Hutin, Y.; Subramanian, T.; Ramachandran, V.; Gupte, M.D. Prevalence of posttraumatic stress disorder in a coastal fishing village in Tamil Nadu, India, after the December 2004 tsunami. Am. J. Public Health 2007, 97, 99-101. [CrossRef]

41. Usami, M.; Iwadare, Y.; Watanabe, K.; Kodaira, M.; Ushijima, H.; Tanaka, T.; Saito, K. Long-term Fluctuations in traumatic symptoms of high school girls who survived from the 2011 Japan tsunami: Series of questionnaire-based cross-sectional surveys. Child Psychiatry Hum. Dev. 2016, 47, 1002-1008. [CrossRef]

42. Armenian, H.K.; Morikawa, M.; Melkonian, A.K.; Hovanesian, A.P.; Haroutunian, N.; Saigh, P.A.; Akiskal, K.; Akiskal, H.S. Loss as a determinant of PTSD in a cohort of adult survivors of the 1988 earthquake in Armenia: Implications for policy. Acta Psychiatr. Scand. 2000, 102, 58-64. [CrossRef]

43. Saxe, G.N.; Ellis, B.H.; Kaplow, J.B. Collaborative Treatment of Traumatized Children and Teens: The Trauma Systems Therapy Approach; Guilford Press: New York, NY, US, 2007.

44. Brown, A.D.; McCauley, K.; Navalta, C.P.; Saxe, G.N. Trauma Systems Therapy in residential settings: Improving emotion regulation and the social environment of traumatized children and youth in congregate care. J. Fam. Violence 2013, 28, 693-703. [CrossRef] [PubMed]

45. Coholic, D.A.; Oystrick, V.; Posteraro, J.; Lougheed, S. Facilitating arts-based mindfulness group activities with vulnerable children: An example of nondeliberative social group work practice. Soc. Work Groups 2016, 39, 155-169. [CrossRef]

46. Salusky, I.; Larson, R.W.; Griffith, A.; Wu, J.; Raffaelli, M.; Sugimura, N.; Guzman, M. How adolescents develop responsibility: What can be learned from youth programs. J. Res. Adolesc. 2014, 24, 417-430. [CrossRef]

(C) 2019 by the authors. Licensee MDPI, Basel, Switzerland. This article is an open access article distributed under the terms and conditions of the Creative Commons Attribution (CC BY) license (http://creativecommons.org/licenses/by/4.0/). 